\title{
Perancangan Aplikasi Monitoring Penerimaan dan Pelaksanaan Proyek Berbasis Web dengan Metode Prototyping Pada PT. Fas Jawara
}

\author{
Agus Waluyo $^{1}$, Aang Munawar ${ }^{2}$ \\ ${ }^{1,2}$ Fakultas Ilmu Komputer, Universitas Budi Luhur \\ 1,2 Jl. Ciledug Raya, Pesanggrahan, Jakarta \\ "1waaluuvoo@gmail.com, ${ }^{2}$ aangmu@gmail.com
}

\begin{abstract}
The rapid development of today's tehnology makes itu possible to tranform a manual system to a computerized system. And it can also be applied to PT.Fas jawara who is still using manual system in recording the receipt of the project, work order making, news making events and invoices. Monitoring the implementation of information systems PT.Fas Jawara can provide benefits that such work would be more effective and efficient. Methodolody of data collection and analysis using theoretical analyzes and acceptance of information systems in general and monitoring projects are running. And inteviews with the company concerned to find out the problems and to investigate the acceptance of business process projects, making work order, create invoices and news system that runs the show. For the analysis and design of information system is using with the object oriented approach where evertything is described in the notation. At least the acceptance of information system and monitoring can runs as excected and allows users to apply.
\end{abstract}

Keywords-information systems, monitoring, design system

\section{PEndahuluan}

Dewasa ini, perkembangan teknologi yang semakin pesat khususnya tentang teknologi informasi dan sistem informasi ternyata masih belum dimanfaatkan secara maksimal oleh sebagian perusahaan yang ada di Indonesia. Pemanfaatan yang kurang ini bisa saja berdampak pada perkembangan suatu perusahaan tersebut. Banyak perusahaan kecil dan menengah yang gulung tikar karena kurang bisa bersaing dengan perusahaan yang besar yang tentunya sudah maju dalam pemanfaatan teknologinya.PT.Fas Jawara merupakan perusahaan swasta yang bergerak dalam bidang jasa instalasi jaringan komputer. Perusahaan tersebut masih menggunakan sistem manual untuk melakukan transaksi dan juga pembuatan pelaporannya, antara lain proses penerimaan pekerjaan, karyawan yang akan mengerjakan, biaya operasional, revenue yang di hasilkan, monitoring proses proyek pekerjaan, membuat berita acara, membuat invoice dan pelaporannya masih menggunakan sistem manual yaitu dengan menggunakan microsoft office excel. Oleh karena itu diperlukan adanya sebuah sistem komputerisasi untuk memberikan solusi dari permasalahan tersebut, yaitu membuat aplikasi yang menangani permasalahan tersebut.Dengan perancangan aplikasi ini diharapkan proses pelaporan kinerja perusahaan dapat berlangsung lebih cepat dan akurat. Sehingga membantu manajer dalam memperoleh informasi perkembangan transaksi yang aktual dan membantu menganalisa perkembangan transaksi yang terjadi pada perusahaan tersebut.

\section{LANDASAN TEORI}

\section{A. Monitoring}

Menurut buku Petunjuk Teknis Monitoring Dan Evaluasi, 2013 yang dikeluarkan Kemendikbud "Monitoring adalah upaya pengumpulan informasi berkelanjutan yang ditujukan untuk memberikan informasi kepada pengelola program dan pemangku kepentingan tentang indikasi awal kemajuan dan kekurangan pelaksanaan program dalam rangka perbaikan untuk mencapai tujuan program" [1].

\section{B. Pengertian Sistem Informasi}

Sistem informasi adalah suatu sistem di dalam suatu organisasi yang mempertemukan kebutuhan pengolahan transaksi harian yang mendukung fungsi operasi organisasi yang bersifat manajerial dengan kegiatan strategi dari suatu organisasi untuk dapat menyediakan laporan-laporan yang diperlukan oleh pihak luar tertentu [2].

\section{Metode Pengembangan Sistem}

\section{1) Metode Waterfall}

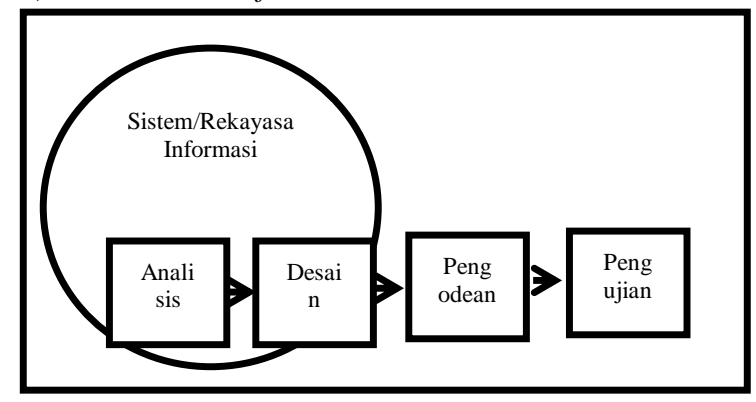

Gambar 1. Ilustrasi Model Waterfall 


\section{a) Analisis Kebutuhan Perangkat Lunak}

Proses pengumpulan kebutuhan dilakukan secara intensif untuk menspesifikasikan kebutuhan perangkat lunak agar dpt dipahami perangkat lunak agar dapat dipahami perangkat lunak seperti apa yang dibutuhkan oleh user. Spesifikasi kebutuhan perangkat lunak pada tahap ini perlu untuk didokumentasikan.

\section{b) Desain Perangkat Lunak}

proses multilangkah yang focus pada desain pembuatan program perangkat lunak termasuk struktur data, arsitektur perangkat lunak, representasi antarmuka dan prosedur pengodean. Tahap ini mentranslasi kebutuhan perangkat lunak dari tahap analisis kebutuhan ke representasi desain agar dapat diimplementasikan menjadi program pada tahap selanjutnya.

\section{c) Pembuatan Kode Program}

Pada tahap ini, desain harus ditranslasikan ke dalam program perangkat lunak.Hasil dari tahap ini adalah program komputer sesuai dengan desain yang telah dibuat pada tahap desain.

\section{d) Pengujian}

Pengujian focus pada perangkat lunak secara dari segi logic dan fungsional dan memastikan bahwa semua bagian sudah diuji. Hal ini dilakukan untuk meminimalisir kesalahan (error) dan memastikan keluaran yang dihasilkan yang dihasilkan sesuai dengan yang diinginkan.

\section{Alat Bantu Pengembangan Sistem}

\section{1) $U M L$}

UML bertujuan untuk memberikan model yang siap pakai, bahasa pemodelan visual yang ekspresif untuk mengembangkan sistem dan yang dapat saling menukar model dengan mudah dan dimengerti secara umum., memberikan bahasa pemodelan yang bebas dari berbagai bahasa pemrograman dan proses rekayasa., menyatukan praktek-praktek terbaik yang terdapat dalam pemodelan.

\section{a) Use Case Diagram}

Use case atau diagram use case merupakan pemodelan untuk kelakuan (behavior) sistem informasi yang akan dibuat. Use Case mendeskripsikan sebuah interaksi antara satu atau lebih actor dengan sistem informasi yang akan dibuat.

\section{b) Activity Diagram}

Definisi diagram aktivitas atau activity diagram adalah diagram yang menggambarkan workflow (aliran kerja) atau aktivitas dari sebuah sistem atau proses bisnis. Yang perlu diperhatikan disini adalah bahwa diagram aktivitas menggambarkan aktivitas sistem bukan apa yang dilakukan actor, jadi aktivitas yang dapat dilakukan oleh sistem.

Simbol berikut adalah simbol yang sering digunakan pada saat pembuatan activity diagram :

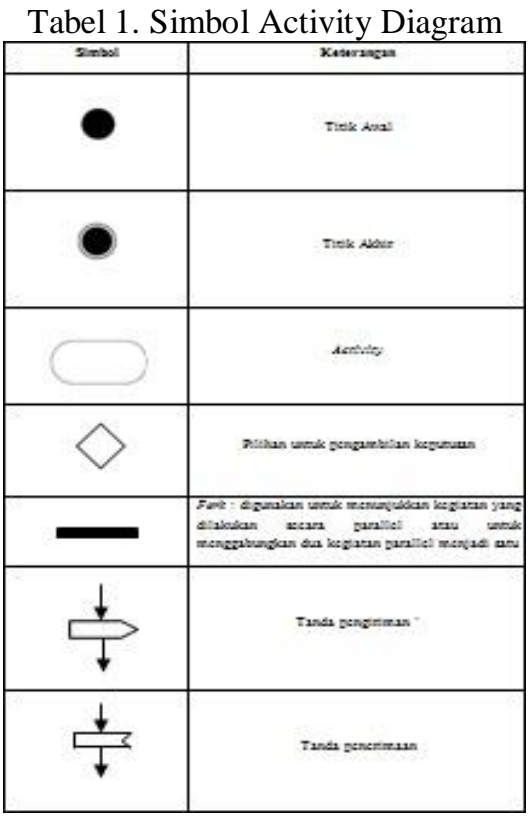

\section{c) Sequence Diagram}

Diagram sekuen atau sequence diagram menggambarkan kelakuan objek pada use case dengan mendeskripsikan waktu hidup objek dan message yang akan dikirimkan dan diterima antar objek.

Simbol berikut adalah simbol yang sering digunakan pada saat pembuatan sequence diagram.

Tabel 2. Simbol yang sering digunakan pada sequence diagram

\begin{tabular}{|c|c|c|}
\hline Noand & Nam Smbor & Restangan \\
\hline Obient! & Objets & 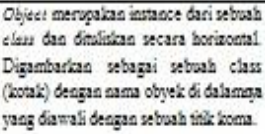 \\
\hline$\frac{9}{\lambda}$ & Astar & 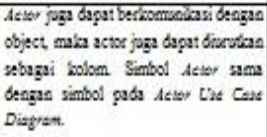 \\
\hline i & Letint & 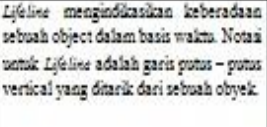 \\
\hline ப & Astriation & 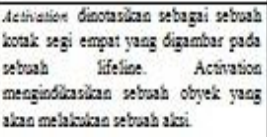 \\
\hline$\stackrel{\text { Nanget }}{\longrightarrow}$ & Mestagt & 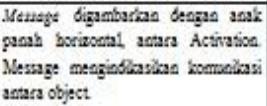 \\
\hline
\end{tabular}




\section{d) Class Diagram}

Diagram kelas atau class diagram menggambarkan struktur sistem dan segi pendefinisian kelas - kelas yang akan dibuat untuk membangun sistem. Kelas memiliki apa yang disebut atribut dan metode atau operasi.

Simbol berikut adalah simbol yang sering digunakan pada saat pembuatan class diagram.

Tabel 3. Simbol Class Diagram

\begin{tabular}{|c|c|c|}
\hline Sinbol & Nama Simbol & Keterangun \\
\hline 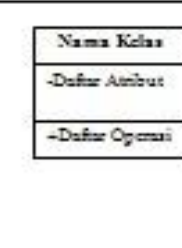 & Closs & 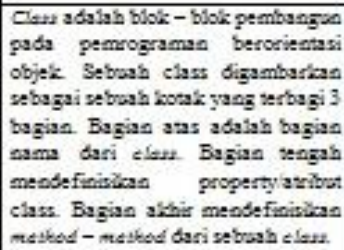 \\
\hline 0.4 & Andetiation & 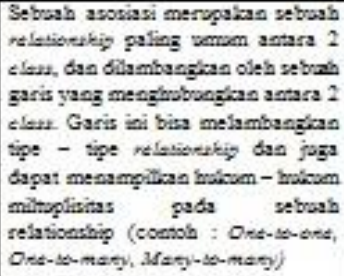 \\
\hline$\rightarrow$ & Dejotndstasy & 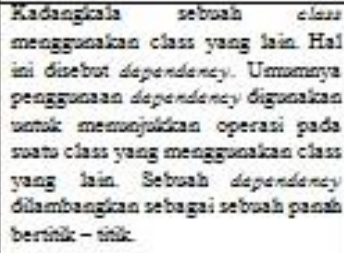 \\
\hline
\end{tabular}

\section{2) $X A M P P$}

XAMPP adalah satu bundle web server yang populer digunakan untuk coba - coba di Windows karena kemudahan instalasinya [3].

\section{3) $\mathrm{PHP}$}

PHP atau yang memiliki kepanjangan PHP Hypertext Preprocessor merupakan suatu bahasa pemrograman yang difungsikan untuk membangun suatu website dinamis [4]. PHP difungsikan sebagai prosesnya sehingga dengan adanya PHP tersebut, web akan sangat mudah dimaintenance.

\section{4) $M y S Q L$}

MySQL adalah salah satu jenis database server untuk membangun aplikasi web yang menggunakan database sebagai sumber dan pengelolaan datanya [5].

\section{ANALISIS DAN PERANCANGAN SISTEM}

PT. Fas Jawara berdiri pada tanggal 7 November 2008.

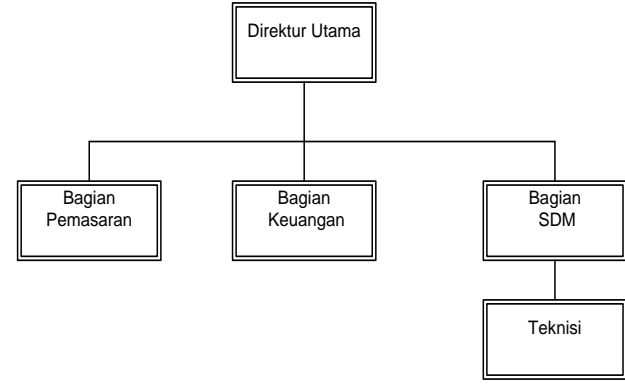

Gambar 2. Struktur Organisasi

Direktur utama bertugas menetapkan dan sebagai penentu keputusan akhir terhadap keputusan. Bagian Pemasaran bertugas menentukan strategi pemasaran yang efektif dan efisien, serta bertanggung jawab terhadap terhadap administrasi pemasaran. Bagian keuangan bertanggung jawab terhadap pemasukan dan pengeluaran keuangan perusahaan. Bagian SDM bertanggung jawab terhadap perekrutan karyawan dan kinerja karyawan. Teknisi melakukan pekerjaan proyek di lapangan.

\section{A. Analisa Sistem Berjalan}

Sampai saat ini pada PT Fas Jawara, cara yang digunakan mulai dari proses penerimaan proyek sampai pembuatan invoice adalah menggunakan cara konvensional yaitu diawali dengan pencatatan data dari pelanggan ke dalam buku PO, kemudian admin menyerahkan catatan tersebut kepada pimpinan untuk mendapatkan persetujuan, apakah pekerjaan itu layak dikerjakan atau tidak. Jika PO disetujui maka admin akan membuat work order dan dicatat ke dalam buku WO.

Langkah selanjutnya yaitu supervisor menunjuk teknisi untuk mengerjakan work order yang dibuat oleh admin.setelah menentukan teknisi, kemudian teknisi mulai mengerjakan proyek pekerjaan yang berasal dari supervisor. Tahapan akhir yaitu admin mencatat semua pengeluaran anggaran yang dibutuhkan selama pengerjaan proyek, dan juga admin membuat berita acara dan invoice yang nantinya akan dikirimkan ke pelanggan.

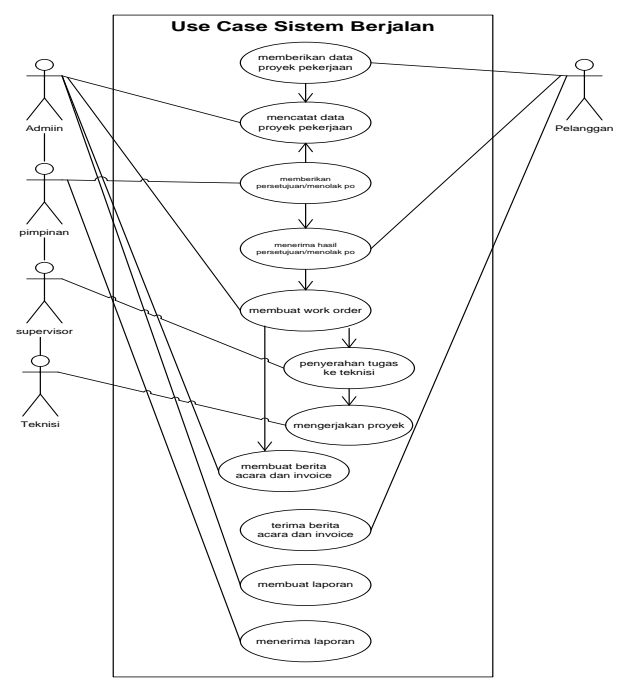

Gambar 3. Use Case Sistem Berjalan 
B. Rancangan Sistem Usulan

1) Use Case

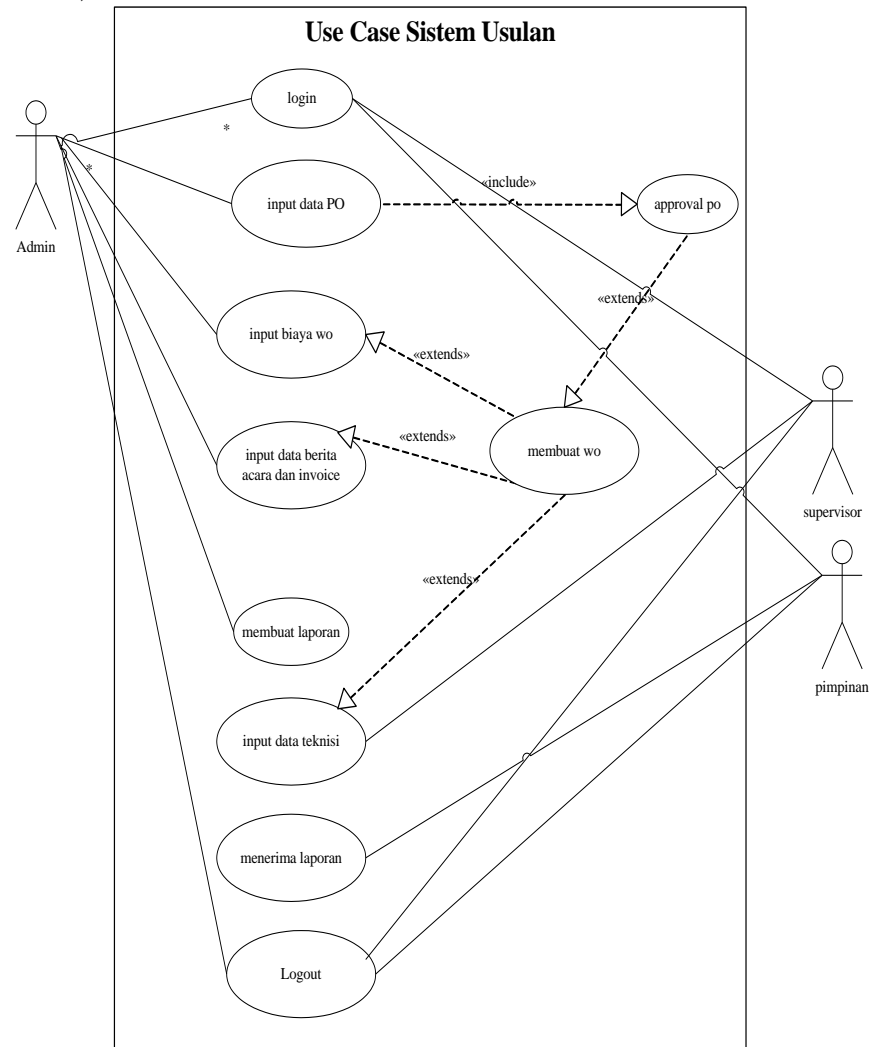

Gambar 4. Use Case Rancangan Sistem Usulan

2) Activity Diagram

a) Login

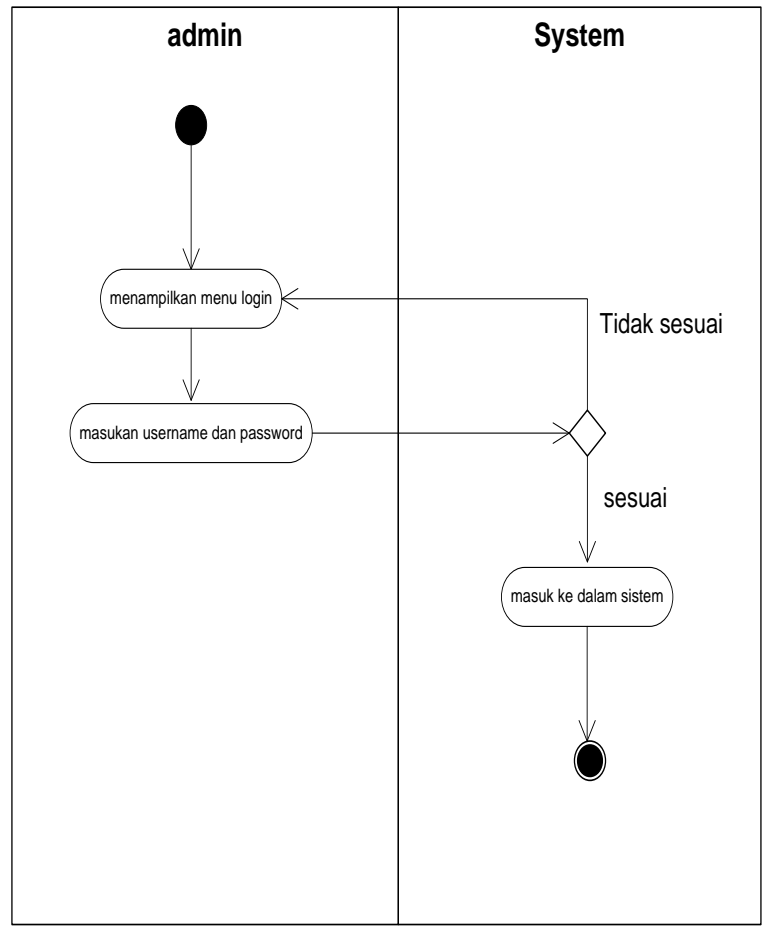

Gambar 5. Activity Form Login b) Input Data PO

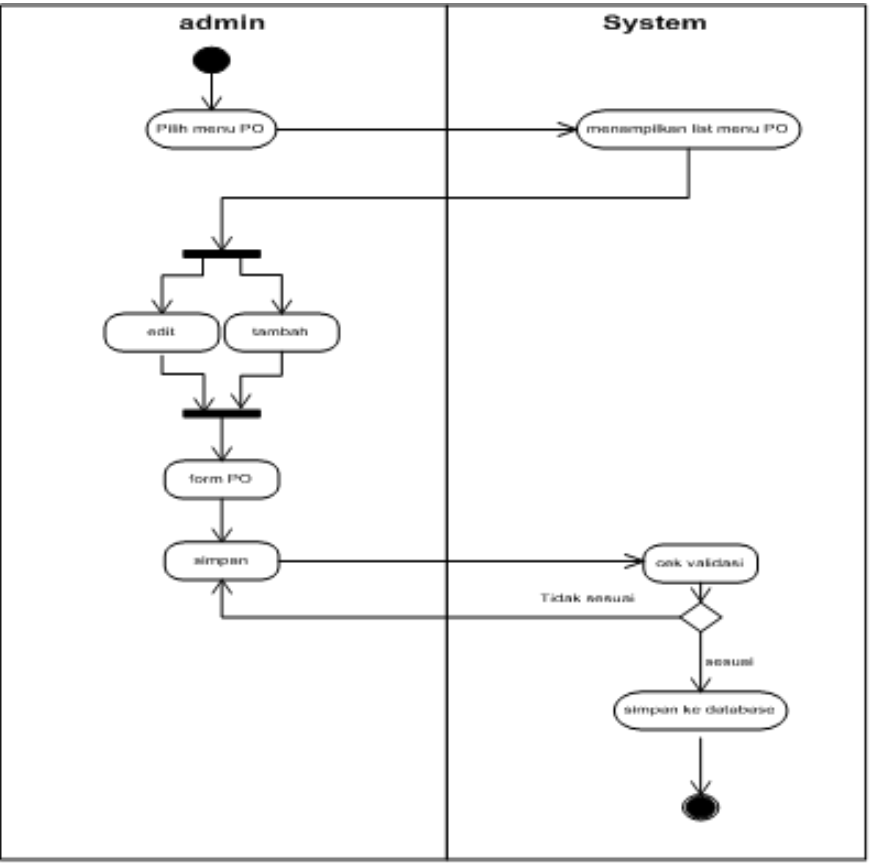

Gambar 6.Activity Diagram Input Data P

c) Input Data WO

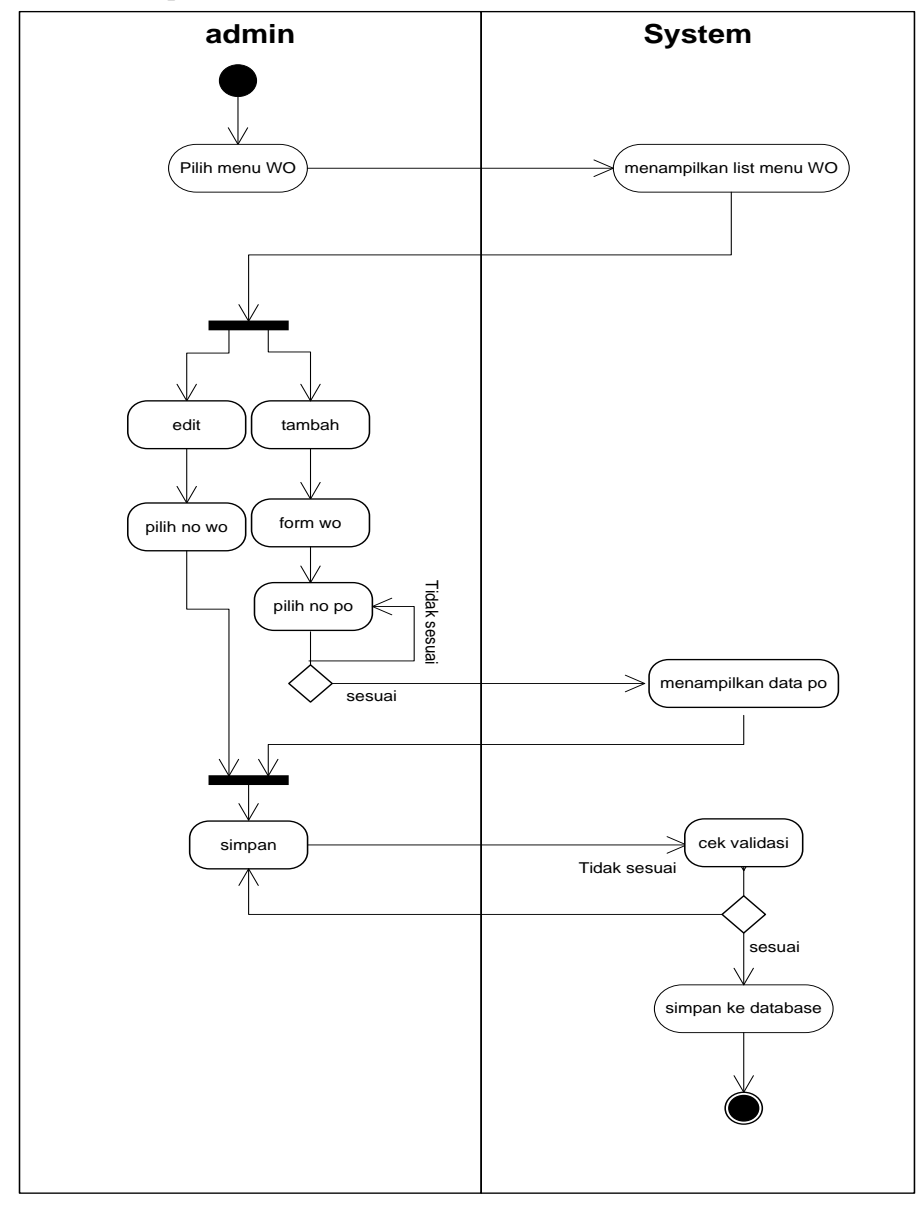

Gambar 7. Activity Diagram Input Data WO 
Jurnal SISFOKOM, Volume 06, Nomor 01, Maret 2017

d) Input Data Biaya WO

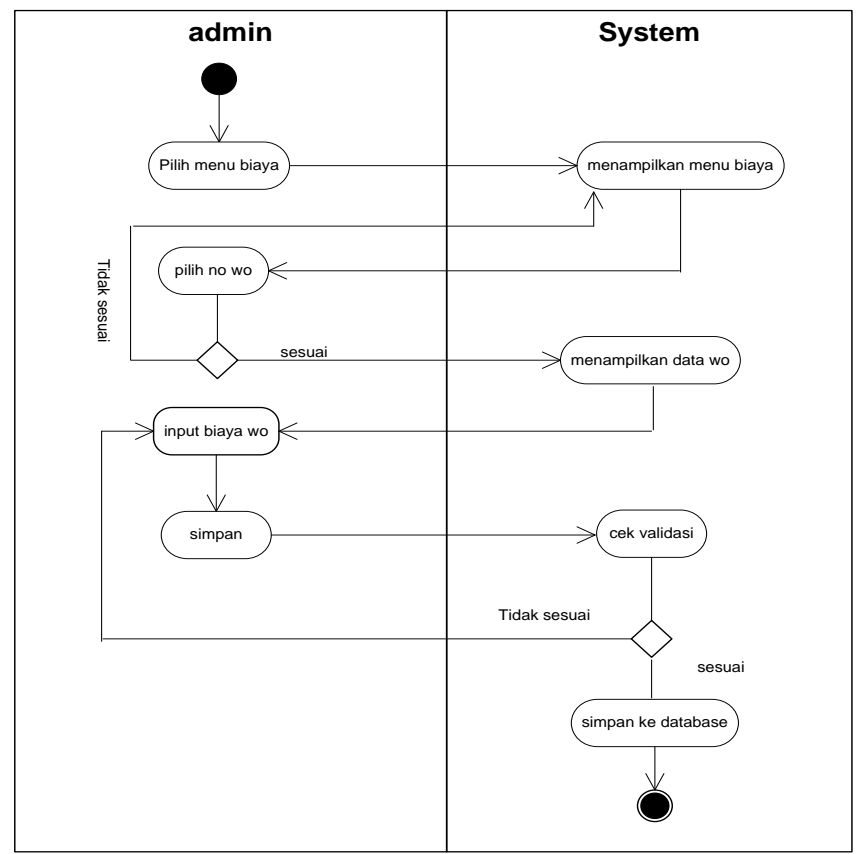

Gambar 8. Activity Diagram Input Biaya WO

\section{Class Diagram}

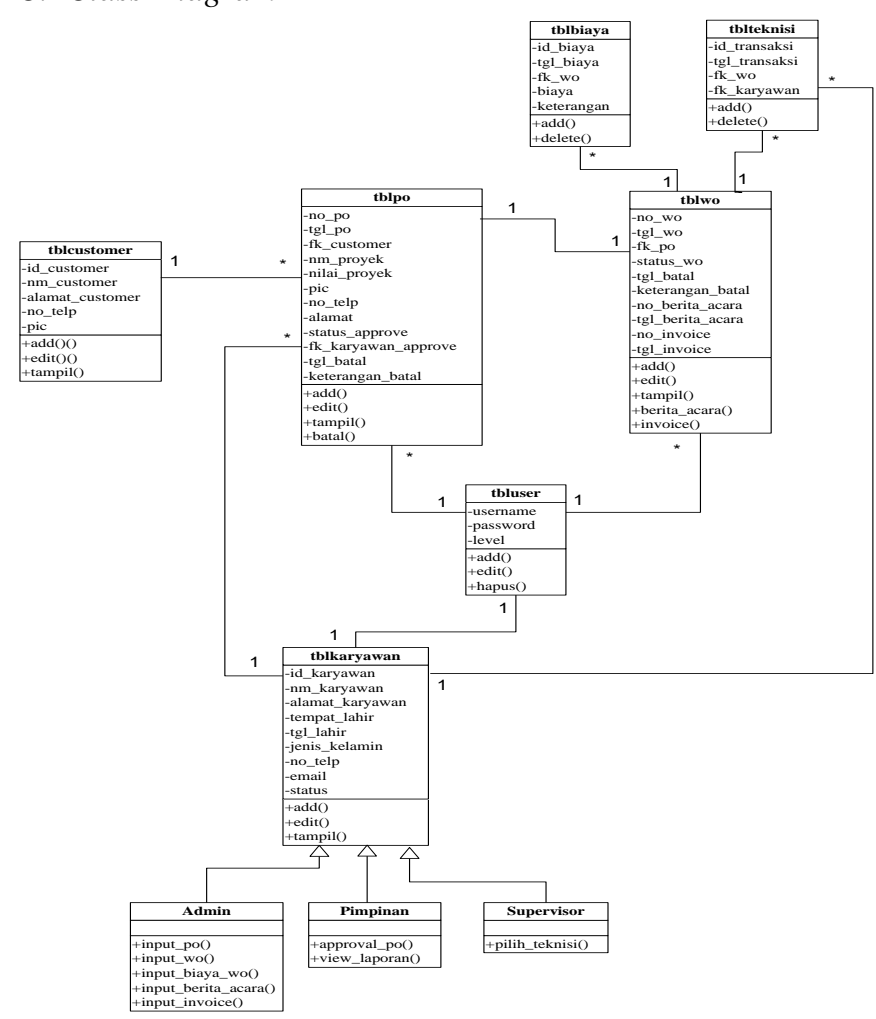

Gambar 9. Class Diagram

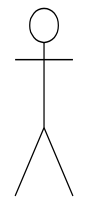

Top Package::admin,pimpinan,supervisor

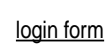

tbluser

Gambar 10. Sequence Buat WO

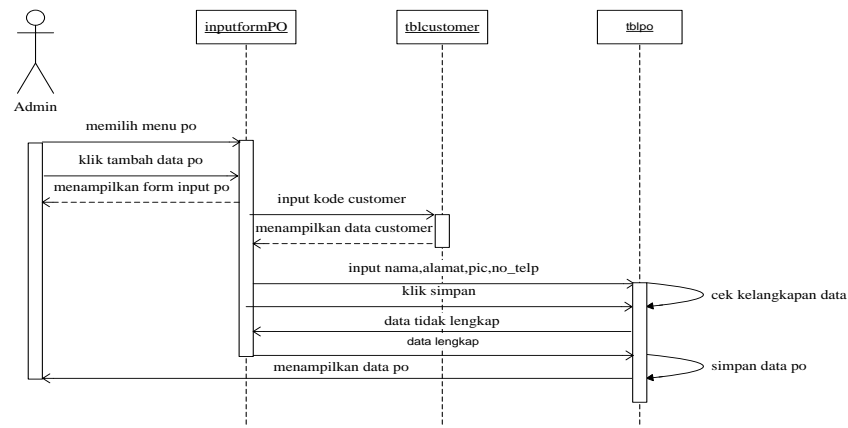

Gambar 11. Sequence Biaya, Berita Acara, dan Invoice

3) Input Data WO

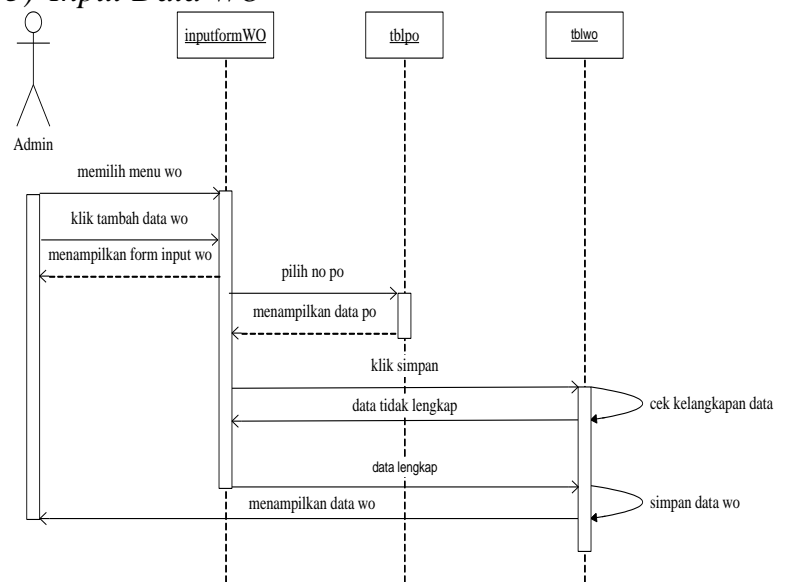

Gambar 12. Input Data WO 
4) Biaya

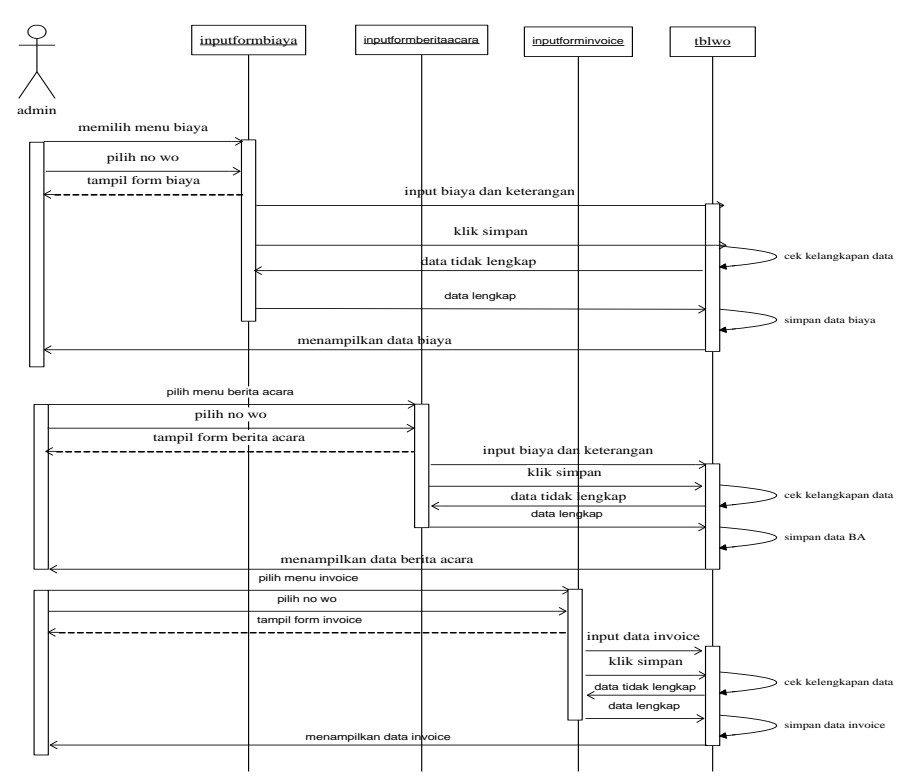

Gambar 13. Sequence Biaya,berita acara dan invoice

\section{IMPLEMENTASI DAN PENGUJIAN}

\section{A. Implementasi Sistem}

Pada tahapan ini proses yang akan dilakukan adalah implementasi dan pengujian pada sistem infomasi monitoring penerimaan dan pelaksanaan proyek sudah dirancang, dengan tujuan untuk menerapkan rancangan sistem informasi kepada sistem yang telah berjalan sehingga user dapat meninjau dan memberikan masukan untuk perkembangan sistem yang telah dibuat.

\section{B. Implementasi Basis Data}

Basis data aplikasi sistem ini menggunakan appserver V2.5.10, beberapa fungsi yang dibuat terdiri dari ruang lingkup implentasi dari aplikasi sistem tersebut.

\section{Implementasi Program}

\section{1) Login}

\section{PT.FAS JAWARA}

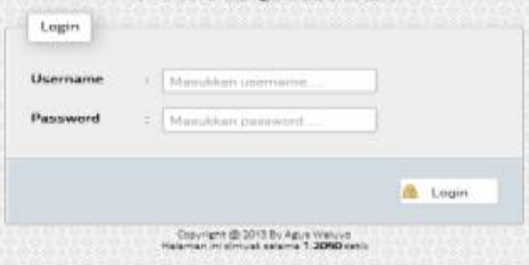

Gambar 14. Halaman Login

\section{2) Input Data PO}

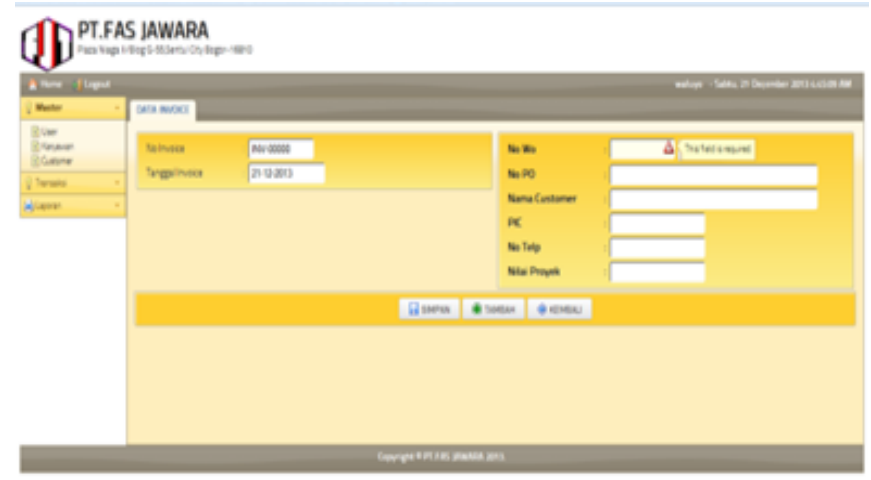

Gambar 15. Input Data PO

\section{3) Input Data WO}

Q1 PI.FAS JAWARA

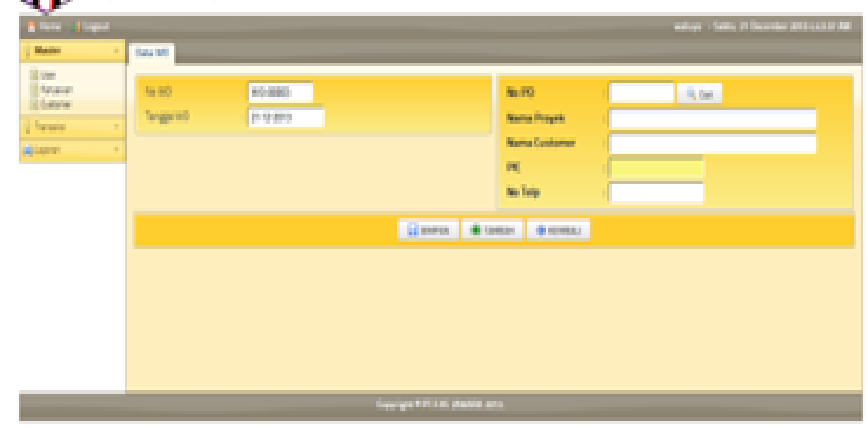

Gambar 16. Input Data WO

\section{4) Input Biaya}

QD PT.FAS IAWARA

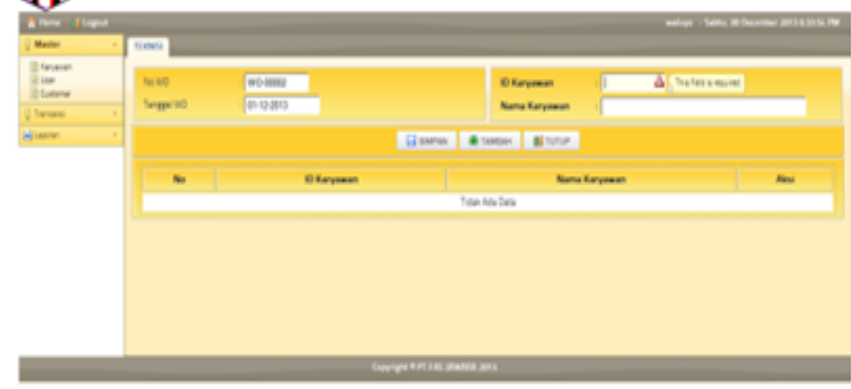

Gambar 17. Halaman Input Biaya

\section{5) Input Berita Acara}

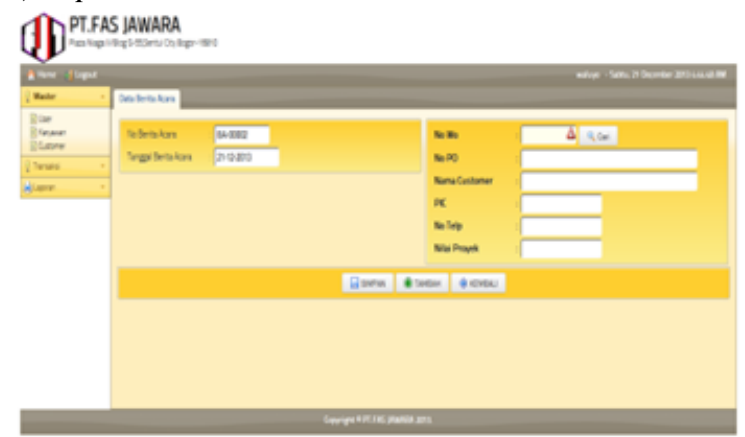

Gambar 18. Halaman Berita Acara 
6) Cetak Invoice

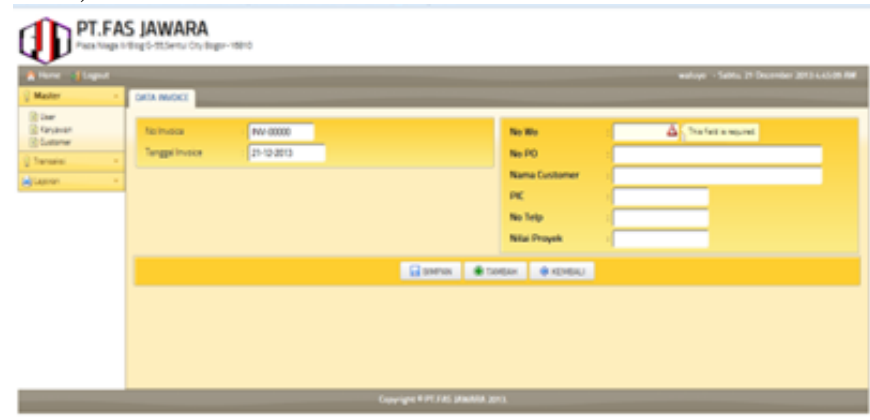

Gambar 19. Halaman Cetak Invoice

\section{Metode Pengujian}

Tahap pengujian dilakukan untuk menguji dan memastikan bahwa program aplikasi web yang telah di rancang dan dikembangkan ini dapat berfungsi dengan baik dan sesuai dengan rumus-rumus rancangan yang telah ditetapkan sebelumnya.. metode yang digunakan yaitu black box test.

Pengujian di lakukan dengan cara memberikan sejumlah masukan (input) pada program aplikasi yang kemudian diproses sesuai dengan kebutuhan fungsionalya untuk melihat apakah program aplikasi web menghasilkan keluaran (output) yang diinginkan sesuai dengan fungsi dari program aplikasi web tersebut.

\section{E. Skenario Pengujian}

Skenario pengujian dilakukan untuk menentukan langkahlangkah dalam melakukan pengujian, yaitu mengeksekusi program dan mengamati setiap input-proses-output yang dieksekusi pada program tersebut.

\section{F. Analisa Hasil Pengujian}

Hasil pengujian yang diperoleh dapat dianalisis sebagai berikut :

- Hasil pengujian berdasarkan pada analisis perancangan sistem sesuai dengan yang diharapkan dan selama pengujian semua tombol serta menumenu berfungsi dengan baik dan berjalan sesuai dengan fungsi-fungsi yang diinginkan. Hal ini terbukti dengan berjalannya aplikasi pada saat implementasi.

- Pada aplikasi yang dibuat dapat menghasilkan beberapa laporan dari setiap data-data yang dientry dan semua data yang dilakukan pada aplikasi monitoring.
- Dengan aplikasi ini pula data-data yang telah di entry dapat tersimpan dengan baik pada database.

\section{PENUTUP}

\section{A. Kesimpulan}

Dari pembahasan pada bab-bab sebelumnya dapat disimpulkan beberapa hal sebagai berikut :

- Aplikasi yang dibangun dapat meningkatkan kecepatan dan efisiensi dalam melakukan pendataan pekerjaan yang diterima oleh perusahaan.

- Aplikasi ini mempermudah perusahaan dalam melakukan perhitungan revenue, pengontrolan biaya dari setiap proyek yang dikerjakan dan mengetahui karyawan yang mengerjakan.

- Aplikasi ini membantu karyawan dalam membuat berita acara dan invoice dengan waktu yang lebih efisien.

- Dapat mempermudah pimpinan dalam melakukan monitoring progres pekerjaan.

\section{B. Saran}

- Harus adanya pemeliharaan terhadap sistem yang telah dibuat agar sistem dapat terjaga dengan baik.

- Untuk mempermudah menjalankan aplikasi, perlu adanya pelatihan bagi karyawan tentang aplikasi yang dibuat.

- Perlu dilakukan pengembangan lebih lanjut tentang aplikasi ini.

\section{DAFTAR PUSTAKA}

[1] Petunjuk Teknis Monitoring Dan Evaluasi. (2013). Jakarta: Kemendikbud.

[2] Prawironegoro, D. d. (2009). Akuntansi Manajemen. Jakarta: Mitra Wacana Media.

[3] Nugroho, A. (2010). Rekayasa Perangkat Lunak Menggunakan UML dan Java. In A. Nugroho, Rekayasa Perangkat Lunak Menggunakan UML dan Java (p. 119). Jogjakarta: Andi OFfset.

[4] Saputra, A. (2012). Membangung Aplikasi Toko Online dengan PHP dan SQL Server. Jakarta: Elexmedia Komputindo.

[5] Arief, M. R. (2011). Pemrogaman Web dinamis Menggunakan PHP dan MySQL. Yogyakarta: Andi. . Yogyakarta: Andi.

[6] Amin, M. M. (2010). In M. M. Amin, Pengembangan Aplikasi Web Menggunakan PHP Data Object (PDO) (p. 2). Yogyakarta: Graha Ilmu.

[7] Aplikasi Web Database Dengan Dreamweaver dan PHP MySq1. (2011). Yogyakarta: Andi dan Madcoms. 